\title{
Efektivitas Permainan Tunjuk Abjad Terhadap Pembelajaran Kosakata Bahasa Mandarin di MA Negeri 1 Cilacap
}

\author{
The Effectivity of Pointing Alpabeth Game towards Chinese Vocabulary Learning \\ in MA Negeri 1 Cilacap
}

Juwita Aprilianti

MAN 1 Cilacap

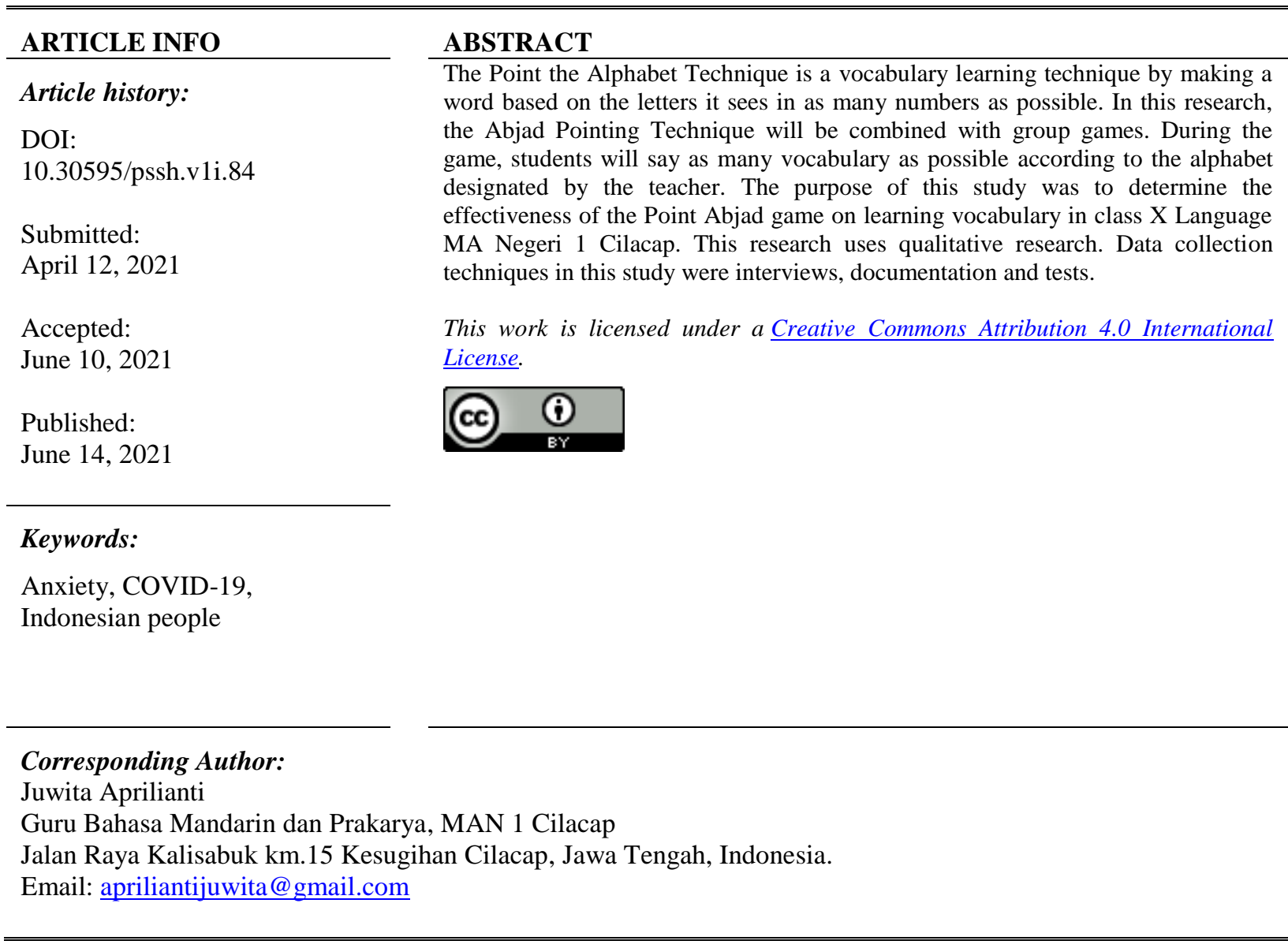

\section{PENDAHULUAN}

Di era sekarang ini penggunaan bahasa asing selain Bahasa Inggris mengalami perkembangan yang pesat. Oleh karena itu, Indonesia memiliki lembaga-lembaga pendidikan, baik formal maupun nonformal, selain mempelajari bahasa Indonesia dan bahasa daerah, juga mulai mempelajari beberapa bahasa asing seperti Bahasa Jepang, Korea, Perancis, Jerman, Mandarin dan lainnya.

Ibraham (2016:15) Terdapat kurang lebih 6.500 bahasa di seluruh dunia. Meskipun begitu, ada sekitar 2000 bahasa yang hanya memiliki penutur kurang dari seribu orang. Adapun bahasa yang paling banyak digunakan manusia di dunia adalah Bahasa Mandarin. Secara keseluruhan, ada setidaknya 1,2 miliar orang yang fasih berbicara bahasa ini.

Ibraham (2016 : 96) Kedudukan Bahasa Mandarin semakin penting seiring meningkatnya kekuatan ekonomi Tiongkok. Pada masa kini, Bahasa Mandarin telah menjadi bahasa yang diprioritaskan untuk diajarkan di berbagai sekolah dan universitas di seluruh dunia. Popularitas ini bukan tanpa alasan. Terdapat lebih dari 1 miliar orang di seluruh dunia yang berbicara dalam Bahasa Mandarin. Artinya, seperlima penduduk bumi mampu menggunakan Bahasa Mandarin. Di Asia, bahasa ini banyak diucapkan oleh penduduk Tiongkok, Taiwan, Malaysia, Singapura, Brunei Darussalam, serta Indonesia. 
Masuknya Bahasa Mandarin dalam lembaga pendidikan merupakan salah satu mata pelajaran pilihan maupun wajib di sekolah tertentu, mulai dari Taman Kanak-kanak (TK), Sekolah Dasar (SD), Sekolah Menengah Pertama (SMP), Sekolah Menengah Atas (SMA) bahkan beberapa Universitas di Indonesia ada yang membuka Program Studi Bahasa Mandarin. Salah satu sekolah yang mempelajari Bahasa Mandarin di Cialcap adalah MA Negeri 1 Cilacap.

MA Negeri 1 Cilacap adalah salah satu MA negeri yang berada di Cilacap. Bahasa Mandarin di MA Negeri 1 Cilacap merupakan mata pelajaran wajib bagi siswa jurusan bahasa. Pengajaran Bahasa Mandarin di MA Negeri 1 Cilacap Tahun Ajaran 2000-2021 dimulai dari kelas X Bahasa, dengan durasi 2 jam pelajaran dalam 1 kali pertemuan setiap pekannya.

Dari hasil wawancara siswa X Bahasa, banyak siswa yang mengalami kesulitan dalam menghafal kosakata Bahasa Mandarin, dengan demikian perlu adanya teknik yang diharapkan dapat menambah semangat dan ketertarikan para siswa dalam belajar kosakata sekaligus diharapkan dapat membantu siswa dalam mengingat kosakata Bahasa Mandarin.

Suyatno (2014:15) Teknik merupakan cara kongkret yang dipakai saat proses pembelajaran berlangsung. Dengan pemilihan teknik yang sesuai, diharapkan dapat memudahkan tujuan pembelajaran. Salah satunya adalah teknik pembelajaran kosakata tunjuk abjad. Teknik Tunjuk abjad merupakan teknik pembelajaran kosakata dengan membuat kata berdasarkan huruf yang dilihatnya dengan jumlah sebanyak-banyaknya, alat/media yang digunakan dalam teknik ini adalah kartu huruf.

Pada penelitian ini, teknik ini di kombinasikan dengan permainan untuk menambah ketertarikan siswa dalam mengikuti pembelajaran Bahasa Mandarin. Teknik Tunjuk Abjad pada penelitian sebelumnya terbukti efektif dalam pembelajaran kosakata Bahasa Mandarin, sedangkan pembelajaran Bahasa Mandarin di MA Negeri 1 Cilacap sebelumnya menggunakan beberapa metode pengajaran seperti ceramah, terjemah, permaianan kata berantai yang di uji coba terbukti efektif dan penggunaan metode pembelajaran kooperatif melalui media gambar pada siswa kelas X Bahasa yang bertujuan untuk meningkatkan kemampuan berbicara Bahasa Mandarin dan perilaku baik siswa. Oleh karena itu pemilihan permainan Tunjuk Abjad ini diharapkan dapat melengkapi metode-metode pengajaran Bahasa Mandarin sebelumya di MA Negeri 1 Cilacap.

Permainan Tunjuk Abjad ini, siswa akan menyebutkan kosakata sebanyak-banyaknya sesuai abjad yang di tunjuk oleh guru. Dengan begitu teknik permainan tunjuk abjad diharapkan dapat meningkatkan penghafalan kosakata Bahasa Mandarin. Seperti tujuan teknik pembelajaran Tunjuk Abjad yang dikemukakan Suyatno (2014:69) yaitu agar siswa dapat memproduksi kata dengan cepat dan banyak dalam waktu yang singkat, sehingga diharapkan dapat memudahkan siswa dalam mengingat kosakata (生词shēngci) yang sudah dikelompokkan sesuai abjad tesebut serta memudahkan peneliti dalam menunjuk abjad secara acak ataupun tidak ketika berlangsungnya permainan, yaitu sesuai nama permainan yang dipakai dalam peneltian ini yaitu permainan Tunjuk Abjad yang pada intinya peneliti menunjuk abjad untuk disebutkan oleh siswa.

Berdasarkan latar belakang diatas diperlukan uji coba keefektifan pembelajaran Tunjuk Abjad untuk meningkatkan kemampuan kosakata. Sehingga peneliti memilih tema dengan judul Efektivitas Permainan Tunjuk Abjad Terhadap Pembelajaran Kosakata Bahasa Mandarin di MA Negeri 1 Cilacap".

\subsection{Rumusan Masalah}

Berdasarkan latar belakang, permasalahan yang hendak diselesaikan melalui penelitian ini dirumuskan ialah bagaimana efektivitas permainan Tunjuk Abjad terhadap pembelajaran kosakata Bahasa Mandarin di MA Negeri 1 Cilacap.

\subsection{Tujuan Penelitian}

Tujuan dalam penelitian ini adalah sesuai dengan rumusan masalah yaitu untuk mengetahui sejauh mana efektivitas permainan Tunjuk Abjad terhadap pembelajaran kosakata Bahasa Mandarin di MA Negeri 1 Cilacap.

\subsection{Manfaat Penelitian}

berikut :

Melalui penelitian ini diharapkan dapat memberikan manfaat secara teoritis dan praktis, sebagai

1. Manfaat Teoritis

Secara teoritis, penelitian ini diharapkan dapat menambah ilmu pengetahuan khususnya dalam bidang pendidikan. Penelitian ini juga sebagai informasi ilmu pengetahuan dan bahan kajian bagi penelitian selanjutnya.

2. Manfaat Praktis

a. Bagi Peneliti

Sebagai penambah pengetahuan dan mengetahui efektivitas pembelajaran Tunjuk Abjad dalam meningkatkan penguasaan kosakata bahasa asing khususnya Bahasa Mandarin.

b. Bagi Siswa 
Penelitian ini diharapkan dapat membantu siswa menumbuhkan motivasi belajar Bahasa Mandarin dalam meningkatkan penguasaan kosakata.

\section{Metode penelitian}

Metode penelitian ini membahas sebagai berikut :

\subsection{Jenis Penelitian}

Penelitian ini menggunakan jenis penelitian kualitatif yaitu pendekatan penelitian yang diarahkan untuk mengetahui efektivitas pembelajaran Tunjuk Abjad dalam meningkatkan penguasaan kosakata bahasa asing khususnya Bahasa Mandarin.

\subsection{Populasi dan Sampel}

\subsubsection{Populasi Penelitian}

Populasi adalah wilayah generalisasi yang terdiri atas : obyek/ subyek yang mempunyai kualitas dan karakteristik tertentu yang ditetapkan oleh peneliti untuk dipelajari dan kemudian ditarik kesimpulannya (Sugiyono 2015 : 217). Populasi pada penelitian ini adalah siswa kelas X Bahasa MA Negeri 1 Cilacap.

\subsubsection{Sampel Penelitian}

Sampel adalah bagian dari jumlah dan karakteristik yang dimiliki oleh populasi tersebut (Sugiyono, $2015: 118$ ). Teknik sampling merupakan teknik pengambilan sampel. Sampel pada penelitian ini adalah seluruh siswa kelas X Bahasa berjumlah 25 siswa.

\subsection{Teknik Pengumpulan Data}

\subsubsection{Wawancara}

Wawancara dilakukan sebagai teknik pengumpulan data apabila peneliti ingin melakukan studi pendahuluan untk menemukan permasalahan yang harus diteliti dan juga apabila peneliti ingin mengetahui hal-hal dari responden yang lebih mendalam dan respondennya sedikit/sangat kecil. Wawancara dapat dilakukan dengan cara terstruktur maupun tidak struktur dan dapat dilakukan melalui tatap muka (face to face) maupun menggunakan telepon (Sugiyono, 2015:194). Dalam penelitian ini peneliti melakukan wawancara terstruktur. Wawancara terstruktur adalah wawancara yang menggunakan pedoman wawancara yang telah disiapkan (Sugiyono, 2015:194-195). Wawancara ini dilakukan dengan siswa kelas X Bahasa saat maupun diluar pembelajaran sebagai berikut:

1. Menanyakan kesukaan siswa pada mata pelajaran Bahasa Mandarin

2. Menanyakan motivasi siswa dalam mengikuti pembelajaran Bahasa Mandarin

3. Menanyakan kesulitan siswa dalam mengikuti pembelajaran Bahasa Mandarin

4. Kesulitan apa saja saat belajar kosakata Bahasa Mandarin

\subsubsection{Teknik Tes}

Pada penelitian ini menggunakan dua tes yaitu pretest ( sebelum diberi perlakuan) dan postest (sesudah diberi perlakuan). Pretest bertujuan untuk mengetahui hasil sebelum adanya perlakuan dan dibandingkan dengan postest yang bertujuan untuk mengetahui hasil setelah diberi perlakuan, untuk mengetahui terdapat perubahan hasil atau tidak. Instrumen tes terlebih dahulu diujicobakan untuk menentukan realibilitas pada instrumen tersebut.

\subsection{Instrumen Penelitian}

Menurut Sugiyono meneliti pada prinsipnya adalah melakukan pengukuran, maka harus ada alat ukur yang baik, sedangkan alat ukur dalam penelitian digunakan mengukur fenomena alam maupun sosial yang diamati. Instrumen tes pada penelitian ini berupa tes kosakata sebagai pretest dan postest. Instrumen ini bertujuan untuk mengetahui perbandingan sebelum pemberlakuan treatment dan sesudah pemberlakuan treatment. Untuk membuat instrumen tes ini terlebih dahulu membuat kisi-kisi soal instrumen. Materi soal untuk membuat instrumen ini diambil dari kosakata. Tes ini terdiri dari pilihan ganda, pilihan yang benar dan menjodohkan. Instrumen tersebut diujicobakan terlebih dahulu sebelum instrumen tes tersebut digunakan untuk diteskan sebagain berikut:

1. Mengetahui pemahaman siswa (arti dan hanzi) dalam penguasaan kosakata

2. Siswa mampu mengetahui makna kosa kata melalui bentuk antonim atau lawan kata

3. Siswa mampu mengetahui 汉字 dan arti dalam gambar kosakata

4. Siswa mampu mengetahui arti dan 汉字 dalam kalimat rumpang pada kalimat tanya

5. Mengetahui pemahaman siswa dalam menyesuaikan gambar dan arti dengan tepat.

6. Siswa mampu meyesuaikan makna kata, maupun hanzi 汉字 aksara Mandarin sesuai gambar.

7. Mengetahui pemahaman siswa dalam mengetahui bentuk tulisan hanzi 汉字 aksara Mandarin yang sesuai dengan bihua拼音 guratan atau goresan.

8. Siswa mampu mengidentifikasi bentuk hanzi 汉字 aksara mandarin untuk mengetahui bihua 拼音 guratan atau goresan.

9. Mengetahui pemahaman siswa dalam menerjemahkan kalimat dengan melengkapi kalimat yang tepat

10. Siswa mampu menerjemahkan kalimat dengan tepat. 
11. Mengetahui pemahaman siswa dalam memaknai kalimat dengan situasi yang ada pada gambar

12. Siswa mampu memaknai kalimat dengan tepat dengan situasi yang ada pada gambar

\section{Hasil Penelitian}

Pada bab ini berisi tentang hasil penelitian "Efektivitas Pembelajaran Tunjuk Abjad terhadap kosakata Bahasa Mandarin di MA Negeri 1 Cilacap" sebagai berikut:

\subsection{Objek Penelitian}

\subsubsection{Gambaran Umum Objek Penelitian}

Penelitian ini dilaksanakan di kelas X jurusan bahasa MA Negeri 1 Cilacap. Peneliti memilih MA Negeri 1 Cilacap karena merupakan salah satu MA Negeri yang tidak hanya mempelajari Bahasa Mandarin tetapi juga bahasa asing lainnya, seperti Bahasa Inggris, Arab dan Perancis.

\subsubsection{Kondisi Responden}

Responden dalam penelitian ini adalah kelas X Bahasa MA Negeri 1 Cilacap. Kelas ini berjumlah 25 siswa yang terdiri dari 9 siswa laki-laki dan 12 siswa perempuan.

\subsection{Langkah-langkah Permainan Tunjuk Abjad}

\subsubsection{Permainan pertama}

Pada permainan pertama Tunjuk Abjad membahas abjad (A, B, C, D, E, F, G, H, J) yang berjumlah 103 kosakata. Pada pertemuan kali ini permainan dimenangkan oleh kelompok 2.

\subsubsection{Permainan kedua}

Pada permainan kedua Tunjuk Abjad membahas abjad (K, L, M, N) yang berjumlah 50 kosakata. Pada pertemuan kali ini permainan dimenangkan oleh kelompok 3.

\subsubsection{Permainan ketiga}

Pada permainan ketiga Tunjuk Abjad membahas abjad (P,Q,R,S ) yang berjumlah 49 kosakata.

Pada pertemuan kali ini permainan dimenangkan oleh kelompok 1.

\subsubsection{Permainan keempat}

Pada permainan ketiga Tunjuk abjad membahas abjad ( T, W, X, Y, Z ) yang berjumlah 97 kosakata. Pada pertemuan kali ini permainan dimenangkan oleh kelompok 1.

\section{HASIL PENELITIAN}

Pada penelitian ini menggunakan dua tes yaitu pretest ( sebelum diberi perlakuan) dan postest (sesudah diberi perlakuan). Dari penelitian yang sudah dilakukan 4 kali pertemuan di kelas X Bahasa MA Negeri 1 Cilacap diperoleh nilai pretest dan postest.

\subsection{Uji Hipotesis}

Untuk mengetahui efektif atau tidaknya permainan Tunjuk Abjad terhadap pembelajaran kosakata Bahasa Mandarin di MA Negeri 1 Cilacap, dalam penelitian ini menggunakan rumus t-test untuk perhitungan pretest dan posttest.

4.2 Perhitungan $t$-test menggunakan rumus (manual)

Sebelum peneliti melakukan perhitungan menggunakan rumus, peneliti terlebih dahulu mempersiapkan tabel persiapan t-test sesuai dengan data yang diperoleh untuk mengetahui data yang dalam dibutuhkan perhitungan rumus. Berdasarkan hasil penelitian membuktikan bahwa "Efektivitas permainan Tunjuk Abjad terhadap kosakata Bahasa Mandarin tidak efektif karena hasil pretest dan posttest tidak menunjukkan perubahan angka atau nilai hasil tes yang signifikan.

\section{PENUTUP}

\subsection{Simpulan}

Berdasarkan hasil penelitian yang telah dilaksanakan, dapat disimpulkan bahwa penerapan permainan Tunjuk Abjad terhadap pembelajaran kosakata Bahasa Mandarin di MA Negeri 1 Cilacap tidak efektif. Hal ini dapat dilihat dari hasil nilai rata-rata pretest dan posttest siswa X Bahasa tidak signifikan.

Hasil pretest menunjukan untuk nilai tertinggi yang diperoleh siswa adalah 97 dan nilai terendah adalah 33, dengan nilai rata-rata 66,3. Sedangkan pada postest, nilai tertinggi yang diperoleh siswa adalah 97 dan nilai terendah adalah 30 dengan nilai rata-rata 69,5.

Dengan demikian, berdasarkan dari hasil penelitian membuktikan bahwa "Efektivitas permainan Tunjuk Abjad terhadap pembelajaran kosakata Bahasa Mandarin” tidak efektif .

\subsection{Saran}

Berdasarkan simpulan dari penelitian ini, saran yang dapat peneliti sampaikan adalah :

(1) Permainan Tunjuk Abjad bisa digunakan pada pembelajaran kosakata bahasa asing lainnya

(2) Bagi calon peneliti selanjutnya yang ingin melakukan penelitian ini, sebaiknya lebih menyesuaikan situasi dan kondisi kelas agar selama melakukan Permainan Tunjuk Abjad siswa tetap terkontrol sehingga kegiatan di dalam kelas tetap kondusif. 
(3) Bagi guru, sebaiknya mencoba menerapkan metode lain seperti metode ice breaking dengan tujuan untuk melatih konsentrasi para siswa, dengan begitu proses pembelajaran akan lebih fokus dan kondusif, dikarenakan ice breaking sendiri bisa digunakan untuk mengembalikan suasana belajar yang fokus dan kondusif.

\section{DAFTAR PUSTAKA}

[1] Ambarwati, Farih Idwi Mei. 2017. Efektivitas Permainanan Kata Berantai terhadap Hasil Belajar Bahasa Mandarin Siswa kelas XI SMA Kebon Dalem Semarang. Skripsi. Universitas Negeri Semarang.

[2] Albastomi, Zazid. 2013. Efektivitas Permainan Tunjuk Abjad Untuk Meningkatkan Kemampuan Kosakata Siswa SMA N 1 Salaman. Skripsi. Universitas Negeri Semarang.

[3] Hanum, Ghiska Nabila. 2015. Efektivitas Permainan Bursa Kata Untuk meningkatkan kemampuan Menguasai Kosa Kata Siswa SMAN 2 Indramayu. Skripsi. Universitas Negeri Semarang.

[4] Megaswari, Riajeng Woro. 2017. Efektivitas Media Permainan Kuis Dalam Meningkatkan Penguasaan Kosa Kata Bahasa Mandarin Untuk Mahasiswa Angkatan 2016. Skripsi. Universitas Negeri Semarang.

[5] Prima, Manda. 2016. Analisis Kesulitan Mahasiswa Semester VI Angkatan 2013 Prodi Pendidikan Bahasa Mandarin Universitas Negeri Semarang dalam Memahami Teks Membaca (阅读) Pada Xin Hanyu Shuiping Kaoshi (新汉语水平考试) Level IV. Skripsi. Universitas Negeri Semarang.

[6] Sari, Rani Oktaviani. 2017. Efektivitas Permainan Bingo Sebagai Media Pembelajaran Untuk Meningkatkan Penguasaan Kosakata Hanzi Pinyin Bahasa Mandarin di SD Islam Program Khusus Muhammadiyah Delanggu Klaten. Skripsi. Universitas Negeri Semarang.

[7] Setyorini, Yun. 2017. Efektivitas Permainan Kartu hànzi Pada Tahap Apersepsi Dalam Peningkatan Penguasaan Kosa Kata Bahasa Mandarin Siswa Kelas X SMA Nusa Putera Semarang. Skripsi. Universitas Negeri Semarang.

[8] Thatsa, Annisa. 2013. Efektivitas Penggunaan Teknik Permainan Alphabet Race Dalam Meningkatkan Kosa Kata Bahasa Jepang. Skripsi. Universitas Pendidikan Indonesia. http://repository.upi.edu/3569/ (diakses pada tanggal 20 Maret 2018 03:30)

[9] Ahmad, Arifin. 2017. "Penerapan Permainan Bahasa (KATARSIS) Untuk Meningkatkan Ketrampilan Membaca Siswa Kelas IV A SD Negeri Mertro Pusat". Universitas Pasundan. http://ejournal.upi,edu/index.php/eduhumaniora/article/dowload/704/4893. (diakses pada tanggal 15 Mei 2018)

[10] Darfilal, Ilhem. 2014/2015. "The Effectiveness of Using Language Games in The Teaching Vocabulary the Case of Third Year Middle School Learness". University of Tlemcen. http://dspace.univtlemen.dz/bitstream/112/7872/darf.pdf ( diakses pada tanggal 20 maret 2018)

[11] Wiratmoko, Ario.2012. "Pengaruh Kegiatan Ekstrakurikuler Robotika Terhadap Kecerdasan Emosional Siswa Di SMK Negeri Yogyakarta”. Skripsi. Universitas Negeri Yogyakarta. http://eprints.uny.ac.id/7710/01cover07501241011 (11 januari 2018)

[12] https://wikipedia.comwikiHanyu_Shuiping_Kaoshi (diakses pada tanggal 23 November 2017)

[13] https://baike.baidu.com/item/中国汉语水平考试/286234?fromid=中国汉语水平考试 \&fromi=96607\&f=allad in (diakses pada tanggal 23 November 2017)

[14] https://baike.baidu.com/item/词汇(diakses pada tanggal 25 November 2017)

[15] http://waitukanarakian.blogspot.com/201/01/kegiatan-ekstrakurikuler.html (11 Januari 2018)

[16] http://Blog.uny.ac.id/fadillahkurniawan/2010/08/31/ekstra-kurikuler-sebagai-wahana-pembentukan-karaktersiswa-di-lingkungan-pendidikan-sekolah/ ( (Faidillah Kurniawan dan Trihadi Karyono), diakses pada tanggal 11 Januari 2018)

[17] https://www.konsistensi.com/2014/03/uji-paired-sample-t-test-dengan-spss.html?m=1 (diakses pada tanggal 14 November 2018 Pukul 2018)

[18] https://www.statistikesehatan.com/uji-t-berpasangan-paired-t-test-spss-mudah-lengkap/ (diakses pada tanggal 21 November 2018) 